\title{
Impact of subcuticular skin suturing in comparison to interrupted suturing on postpartum inflammation of episiotomy
}

\begin{abstract}
Introduction: Episiotomy is an incision in perineal area in second stage of labour.

Aim of the work: To detect the effect of interrupted method of skin suturing versus Subcuticular method of episiotomy closure on post delivery echymosis, redness and edema.

Patients and methods: All patients were delivered by normal vaginal delivery and a medio lateral episiotomy was made and then closure of the episiotomy was done using either a subcuticular or interrupted technique according to the group using Vicryl 3-0.

Results: There was no significant difference between the postpartum edema after 7 days in the interrupted group when compared to the continous group with a $\mathrm{P}$ value 0.416

Conclusion: There was no significant difference between the interrupted method of closing episiotomy and subcuticular way on postoperative inflammation.
\end{abstract}

Volume 9 Issue 6 - 2018

\author{
Mahmoud Alalfy,' Ahmed El lithy, ${ }^{2}$ Ahmed \\ Hassan, ${ }^{3}$ Amr Abbassy \\ 'Lecturer (Researcher) of Obstetrics and Gynecology, \\ Department of reproductive Health and family planning \\ National Research Centre, Consultant Obstetrics and \\ Gynecology,Aljazeerah Hospital, Egypt \\ ${ }^{2}$ Assistant professor of Obstetrics and Gynecology, Faculty of \\ Medicine, Cairo University, Egypt \\ 'Lecturer of Obstetrics and Gynecology, Faculty of Medicine, \\ Helwan University, Consultant Obstetrics and Gynecology, \\ Aljazeerah Hospital, Egypt
}

Correspondence: Mahmoud Alalfy, Lecturer (Researcher) of Obstetrics and Gynecology, Reproductive Health and family planning department, National Research Centre, Consultant Obstetrics and Gynecology, Aljazeerah Hospital, Egypt, Tel 010026II058,Emailmahmowdalalfy@ymail.com

Received: October 29, 2018 | Published: November 16,2018

\section{Introduction}

Episiotomy is an incision that is made in perineum at second stage of delivery. There are Long term sequels of episiotomy repair. A considerable number of women experience perineal pain and up to 20 percent have long term sequels e.g., dyspareunia. ${ }^{1}$

The best method for repairing episiotomy is the method that is not time consuming and lesser materials and causes lesser pain in the immediate and long term periods. And so helps to start sexual relation early with a lesser pain and has a lower chance for resuturing. ${ }^{2}$

There was a traditional technique that was used for episiotomy repair with applying 3 layers closure technique. ${ }^{3}$

Although there are many ways to repair episiotomy, Now two widely used techniques of closure are applied; subcutaneous continuous and interrupted techniques. ${ }^{4}$

\section{Patients and methods}

This was a prospective multi centric randomized study that was made in Aljazeerah hospital, Kasr alainy hospital and Helwan university hospitals, Egypt in the period from June 2017 till July 2018. 166 pregnant women were recruited to participate in this study, and were consented before sharing in the study, the Allocation and Randomization; a computer generated randomization table was used for allocation in each study arm implementing a closed envelope system opened by operating room nurse during the time of randomization. The randomization allocation was $1: 1$. The two groups were randomly selected, 83 in each group. 6 cases dropped out from follow up and did not come to the hospital to follow post delivery, so they were excluded from the study and 160 cases continue the study.

All patients were delivered by normal vaginal delivery and a medio lateral episiotomy was made and then closure of the episiotomy was done using either a subcuticular or interrupted technique according to the group using Vicryl 3-0.

In the regular follow up of patients, they were examined to assess echymosis, redness and edema at the episiotomy site 7 days post delivery.

Inclusion criteria, a primigravida pregnant 38 weeks or more with no medical disorders with pregnancy with cephalic presentation, BMI below 25 .

Exclusion criteria include preterm delivery, any medical disorders with pregnancy, twin pregnancy, fetuses with malpresentation, previous cesarean section (Figure 1).

\section{Statistical methods and sample size calculation}

Data were coded and entered using the statistical package SPSS version 25. Data was summarized using mean and standard deviation for quantitative variables and frequencies (number of cases) and relative frequencies (percentages) for categorical variables. Comparisons between groups were done using unpaired test (Chan, 2003). ${ }^{5}$ For comparing categorical data, Chi square $\left(\chi^{2}\right)$ test was performed. Exact test was used instead when the expected frequency is less than 5 (Chan, 2003). ${ }^{6} \mathrm{P}$-values less than 0.05 were considered as statistically significant. ${ }^{5,6}$

Sample size was calculation was done using the comparison between subcuticular skin suturing and interrupted suturing on postpartum inflammation of episiotomy as reported in a previous publication made by Alkhafaji $\mathrm{ZHH},{ }^{7}$ the proportion of wound infection in subcuticular skin suturing is $2 \%$ while the proportion of wound infection in interrupted suturing is $14.5 \%$, accordingly, we calculated that the minimum proper sample size needed to be 150 
patients to be able to reject the null hypothesis with $80 \%$ power $(\beta=$

$0.2)$ and $95 \%$ significance level $(\alpha=0.05)$.sample size was increased

to allow for drop out, the total sample size was 200 patients. $^{7}$



Figure I Consort flow diagram.

\section{Results}

The present study was a prospective multi centric randomized study that was made in Aljazeerah hospital, Kasr alainy hospital and Helwan university hospitals, Egypt in the period from June 2017 till July 2018. Among 166 pregnant women that were recruited to participate in this study, the mean value of number of sutures was $7.34+/-.67$ and the mean value of length of delivery was $12.04+/-$ 3.11 as mentioned in Table 1.

There were no statistically significant difference between patients of both groups regarding age, BMI, number of sutures, blood loss and length of delivery as demonstrated in Table 2 .

The total number of cases that had redness, edema and echymosis was 10,15 and 14 cases respectively as shown in Table 3 .

The comparative analysis of subcuticular group versus interrupted group as regard post delivery complications is illustrated in Table 4.

Table I Shows Description of data

\begin{tabular}{llll}
\hline & Mean & Standard deviation & $\%$ \\
\hline Age & 28.3 & 5.25 & \\
Gravidity \& parity & Multigravida & 54 & $33.80 \%$ \\
& Primigravida & 106 & $66.20 \%$ \\
BMI & 21.79 & 1.8 & \\
Length of delivery (hours) & 12.04 & 3.11 & \\
Blood loss (CC) & 560.63 & 147.02 & \\
Number of sutures & 7.34 & 0.67 & \\
\hline
\end{tabular}


Table 2 Shows the mean and standard deviation and $P$ value between 2 groups

\begin{tabular}{|c|c|c|c|c|c|}
\hline & \multicolumn{4}{|c|}{ Technique of closure } & \multirow{3}{*}{$P$ value } \\
\hline & \multicolumn{2}{|c|}{ Continous (subcuticular) } & \multicolumn{2}{|c|}{ Interrupted } & \\
\hline & Mean & Standard Deviation & Mean & Standard Deviation & \\
\hline Age & 29.08 & 5.57 & 27.53 & 4.83 & 0.062 \\
\hline BMI & 21.62 & 1.77 & 21.96 & 1.83 & 0.237 \\
\hline Length of delivery (hours) & 11.73 & 3.35 & 12.35 & 2.82 & 0.204 \\
\hline blood loss (CC) & 566.25 & 155.65 & 555 & 138.62 & 0.63 \\
\hline number of sutures & 7.4 & 0.59 & 7.27 & 0.75 & 0.241 \\
\hline
\end{tabular}

Table 3 Shows analysis of cases regarding gravidity, technique of skin closure and presence of complications

\begin{tabular}{llll}
\hline & & Count & $\%$ \\
\hline \multirow{2}{*}{ Gravidity \& parity } & multigravida & 54 & $33.80 \%$ \\
& primigravida & 106 & $66.20 \%$ \\
Technique of closure & Continous (subcuticular) & 80 & $50.00 \%$ \\
& interrupted & 80 & $50.00 \%$ \\
Redness & yes & 10 & $6.20 \%$ \\
Edema & No & 150 & $93.80 \%$ \\
& yes & 15 & $9.40 \%$ \\
Echymosis & no & 145 & $90.60 \%$ \\
& yes & 14 & $8.80 \%$ \\
\hline
\end{tabular}

Table 4 Comparison between the 2 groups regarding presence of redness, edema and echymosis

\begin{tabular}{|c|c|c|c|c|c|c|}
\hline & & \multicolumn{4}{|c|}{ Technique of closure } & \multirow{3}{*}{$P$ value } \\
\hline & & \multicolumn{2}{|c|}{ Continous (subcuticular) } & \multicolumn{2}{|c|}{ Interrupted } & \\
\hline & & Count & $\%$ & Count & $\%$ & \\
\hline \multirow{2}{*}{ Gravidity \& parity } & multigravida & 28 & $35.00 \%$ & 26 & $32.50 \%$ & \multirow{2}{*}{0.738} \\
\hline & primigravida & 52 & $65.00 \%$ & 54 & $67.50 \%$ & \\
\hline \multirow{2}{*}{ Redness } & yes & 6 & $7.50 \%$ & 4 & $5.00 \%$ & \multirow{2}{*}{0.514} \\
\hline & No & 74 & $92.50 \%$ & 76 & $95.00 \%$ & \\
\hline \multirow{2}{*}{ Edema } & yes & 9 & II. $20 \%$ & 6 & $7.50 \%$ & \multirow{2}{*}{0.416} \\
\hline & no & 71 & $88.80 \%$ & 74 & $92.50 \%$ & \\
\hline \multirow[t]{2}{*}{ Echymosis } & yes & 8 & $10.00 \%$ & 6 & $7.50 \%$ & \multirow{2}{*}{0.576} \\
\hline & no & 72 & $90.00 \%$ & 74 & $92.50 \%$ & \\
\hline
\end{tabular}

\section{Discussion}

In the present study, the number of sutures has no statistical significance with a $\mathrm{P}$ value 0.241 , indicating that there was no difference in presence of redness, echymosis or edema postoperatively with different suture number.

In agreement with our study, South mead perineal suture research found that there was no change between the subcuticular and interrupted sutures results. ${ }^{8}$

In the present study, there was no significant difference between the postpartum edema after 7 days in the interrupted group when compared to the continous group with a $\mathrm{P}$ value 0.416 .

RCOG 2004 guideline also given level A gradation to the use of continuous subcuticular technique for perineal skin closure and a loose, continuous non locking suturing technique to appose vaginal tissue and perineal muscle as it is associated with less short term pain compared with the interrupted method. ${ }^{9}$

In the present study, there was no significant difference between the postpartum redness after 7 days in the interrupted group when compared to the continous group with a $\mathrm{P}$ value 0.514 . 
In Pakistan, a previous research compared the methods of closure in interrupted and continous closure ways of episiotomy on the 6th and on the 10th day and after delivery. Similar to our results, they did not find a significant difference in the rate of healing of wound. ${ }^{10}$

In a previous study made concluded that wound gaping was recorded in 5 women sutured with $\mathrm{CC}$, whereas, none of the women sutured with VR showed gaping of their episiotomy wound. ${ }^{11}$

Also in the current study, there was no statistical significance between the interrupted method and subcuticular method regarding presence of echymosis 7 days post delivery with a $\mathrm{P}$ value 0.576 .

\section{Conclusion}

Our study revealed that there is no statistically significant difference between the interrupted method of closing episiotomy and subcuticular way on postoperative inflammation.

\section{Author contribution}

The team of authors participated in this study in its aspects with

Substantial contributions to the conception or design of the work; or the acquisition, analysis, or interpretation of data for the work; AND

1. Drafting the work or revising it critically for important intellectual content; AND

2. Final approval of the version to be published; AND

3. Agreement to be accountable for all aspects of the work in ensuring that questions related to the accuracy or integrity of any part of the work are appropriately investigated and resolved.

In addition to the above mentioned participation of the authors, Obstetrician performed the follow up of the cases and performing the delivery.

\section{Acknowledgments}

The authors would like to thank all medical staff members who helped us in completing this research.

\section{Disclosure statement}

All authors declare that there are no any financial and personal relationships with other people or organizations that could inappropriately influence (bias) their work.

\section{Conflict of interest}

The authors declare that they have no conflict of interest.

\section{References}

1. Kalis et al. Material and type of suturing of perineal muscles used in episiotomy repair in Europe. Pelviperineology. 2008;27:2-17.

2. Valenzuela P, Saiz Puente MS, Valero JL, et al. Continuous versus interrupted sutures for repair of episiotomy or second-degree perineal tears: a randomised controlled trial. BJOG. 2009;116(3):436-441.

3. Zafar S. Comparison of single knot versus three layered techniques of perineal repair after vaginal delivery in women requiring episiotomy. $J T$ Urkish-German Gynaecol Asso. 2008;9(3):129-133.

4. Signorello LB, Harlow BL, Chekos AK, et al. Postpartum sexual functioning and its relationship to perineal trauma: a retrospective cohort study of primiparous women. Am J Obstet Gynecol. 2001;184(5):881-888.

5. Chan YH. Biostatistics 102: quantitative data - parametric \& nonparametric tests. Singapore Med J. 2003;44(8):391-396.

6. Chan YH. Biostatistics 103: qualitative data -tests of independence. Singapore Med J. 2003;44(10):498-503.

7. Al-Khafaji ZHH. A comparative study of two different, methods for episiotomy repair. Karbala J Med. 2008;2(4,5):280-288.

8. Mahomed A, Grant A, Ashurt H, et al. The Southmead perineal suture study. A randomized comparision of suture materials and suturing techniques for repair of perineal trauma. Br J Obstet Gynaecol. 1989;96:1272-1280.

9. Royal College of Obstetricians and Gynaecologists. Green-top Guideline No. 29: The management of third- and fourth-degree perineal tears. RCOG; 2007:1-11.

10. Perveen F, Shabbir T. Perineal repair: comparsion of suture materials and suturing techniqus. $J$ Surgery Pakistan. 2003;14(1):23-28.

11. Bose E, Samant M, Lal P, et al. Comparison of impact of polyglactin 910 (Vicryl rapide) and chromic catgut sutures on perineal pain following episiotomy wound repair in eastern Indian patients. J Sci Soc. 2013;40:9598. 